\title{
Pancreatic Necrotic Lesion
}

National Cancer Institute

\section{Source}

National Cancer Institute. Pancreatic Necrotic Lesion. NCI Thesaurus. Code C78522.

A necrotic process affecting the pancreas. 